CELL BIOLOGY,

REGENERATIVE

MEDICINE
Citation: Petrova, E., Isaeva, E., Kolos, E. and Korzhevskii, D. 2018. Allogeneic bone marrow mesenchymal stem cells in the epineurium and perineurium of the recipient rat. Bio. Comm. 63(2): 123-132. https://doi.org/10.21638/spbu03.2018.205

Author's information: Elena Petrova Senior Researcher, orcid.org/0000-00030972-8658; Elena Isaeva, Researcher; Elena Kolos, Junior Researcher, orcid.org/0000-0002-9643-6831 Dmitrii Korzhevskii, Doctor of Medicine (MD), Professor of the Russian Academy of Sciences, Laboratory Head, orcid.org/00000002-2456-8165

Manuscript Editor: Raul Gainetdinov, Saint Petersburg State University, Saint Petersburg, Russian Federation

Received: May 31, 2018;

Revised: June 24, 2018;

Accepted: June 25, 2018;

Copyright: (c) 2018 Petrova et al. This is an open-access article distributed under the terms of the License Agreement with Saint Petersburg State University, which permits to the authors an unrestricted distribution, and self-archiving free of charge.

Funding: No funding information provided.

Competing interests: The authors have declared that no competing interests exist.

\section{Allogeneic bone marrow mesenchymal stem cells in the epineurium and perineurium of the recipient rat}

\author{
Elena Petrova1, Elena Isaeva ${ }^{2}$, Elena Kolos ${ }^{1}$, and Dmitrii Korzhevskii \\ ${ }^{1}$ Laboratory of Functional Morphology of the Central and Peripheral Nervous System, \\ Institute of Experimental Medicine, ul. Akad. Pavlova, 12, \\ Saint Petersburg, 197376, Russian Federation \\ 2Laboratory of Immunoformacology, Research Institute of Highly Pure Biopreparations, \\ Russian Federal Agency for Medicine and Biology, Pudozhskaya ul., 7, \\ Saint Petersburg, 197110, Russian Federation \\ Address correspondence and requests for materials to Elena Petrova, \\ iemmorphol@yandex.ru
}

\begin{abstract}
Achievements in regenerative medicine have demonstrated that using different kinds of stem cells can have some stimulating effect on the reparative regeneration processes of the nervous system. To stimulate nerve regeneration, the experimental elaboration of mesenchymal stem cell (MSC) transplantation is carried out actively. There is evidence that MSCs promote growth of the recipient regenerating axons after transplantation into the damaged nerve or the conduit. However, processes that happen in transplanted cells and these cells' differentiation are poorly studied. The aim of the present study is to describe the localization and morphologically peculiar properties of bone marrow-derived mesenchymal stem cells after their allotransplantation into the injured nerve of a rat. MSCs from Wistar-Kyoto rats were cultivated for seven days and labeled with BrdU three days before using. The sciatic nerves of adult Wistar-Kyoto rats were damaged, and suspensions of BrdU-labeled cultured MSCs were immediately transplanted into the damaged sciatic nerves. Five to seven days after transplantation, the surviving MSCs were found. Using fluorescent microscopy, we found that some of the transplanted cells were localized in the epineurium and in the perineurium. Some of the transplanted MSCs differentiated into adipocytes and cells of the perineurium.
\end{abstract}

Keywords: MSCs, differentiating, nerve, epineurium, perineurium, adipocytes, immunohistochemistry, fluorescence microscopy.

\section{Introduction}

Modern regenerative medicine has demonstrated that transplantation of different kinds of stem cells can have a stimulating effect on the processes of reparative regeneration of the central and peripheral nervous system (Southwell et al., 2014; $\mathrm{Li}, \mathrm{Hu}$, and Cheng, 2015; Sokolova and Polyntsev, 2017). In recent years, experimental elaboration of different cellular technologies to stimulate regeneration of damaged nerves is being carried out intensively. There are many reviews on this issue (Walsh and Midha, 2009; Petrova, 2012; Fairbairn et al., 2015, Shchanitsyn et al., 2017; Petrova, 2018). There is evidence that mesenchymal stem cells (MSCs), derived from bone marrow, adipose tissue, umbilical cord stroma, amniotic fluid and other tissues, promote growth of the recipient regenerating axons after transplantation into a damaged nerve or into a conduit (Dezawa et al., 2001; Kingham et al., 2007; Chen et al., 2007; Wong et al., 2011; Masgutov et al., 2018). The stimulating effect of MSCs on repair processes in nervous tissue is explained by their properties. MSCs are able to produce neurotrophic and angiogenic substances. 
It has been shown that they release brain-derived neurotrophic factor (BDNF), glial cell-derived neurotrophic factor (GDNF), vascular endothelial growth factor-A (VEGF-A), and angiopoietin-1 proteins (Kingham et al., 2007). It has also been found that injection of MSCs into damaged nerves leads to an increase in the number of blood vessels in the distal segment of the injured nerve trunk (Petrova, Isaeva, Kolos, and Korzhevskii, 2018). An important property of MSCs is their ability to modulate the immune response (Stagg and Galipeau, 2013). Clinical use of adipose-derived stem cells and umbilical cord mesenchymal stem cells was the result of experimental studies (Li et al., 2013; Gallyamov et al., 2015). However, the fate of the transplanted cells and their differentiation is poorly studied. Researchers mainly study the cells that are found after transplantation within the endoneurium of a nerve trunk. However, some of the transplanted cells are found in the nerve connective tissue shells of the recipient after their transplantation into the nerve. This fact has been noted only in individual works (Zhang et al., 2004; Petrova, Isaeva, and Korzhevskii, 2016).

The purpose of the present study was to describe the localization and morphological features of bone marrow-derived mesenchymal stem cells after their allotransplantation in damaged nerves of rats.

\section{Material and Methods}

\section{CULTURE OF MSCS}

MSCs derived from bone marrow of Wistar-Kyoto rats were provided by-Trans-Technologies Ltd. (Saint Petersburg, Russia, General Director D. G. Polyntsev). The method of obtaining MSCs and their characteristics were described in more detail earlier by N.Zin'kova et al. (2007). Cells were cultured for a week, using a culture flask (NEST Scientific, USA) and culture medium MEM alpha (BioloT, Russia) supplemented with bovine serum. Three days prior to using the culture, 5-bromo2-deoxyuridine (BrdU) (Sigma, USA) was added to the medium. The MSC suspension was washed twice with the medium without BrdU and centrifuged for $15 \mathrm{~min}$ $(200 \mathrm{~g})$. The precipitate was resuspended in $1 \mathrm{ml}$ of fresh medium, and viability of the cells was tested using $0.2 \%$ trypan blue solution (BioloT, Russia) and by cell calculation in a Goryaev chamber. The cell suspension was used for transplantation if the viability of the latter was at least $90 \%$.

\section{NERVE DAMAGE AND MSC TRANSPLANTATION INTO THE NERVE}

Adult male Wistar-Kyoto rats were used $(n=12)$; their housing and all experiments were carried out according to the rules for work with experimental animals. During all experiments, euthanasia was carried out in compliance with the international regulations of the Declaration of Helsinki on humane treatment of animals and "The rules for conducting studies with the use of experimental animals" (Order no. 755 of 12.08.1977, Ministry of Public Health). The research was approved by the local Ethics Committee of the Institute of Experimental Medicine, St. Petersburg, Russia (Protocol №3/17 of November 30, 2017).

The method of transplantation of MSCs was performed according to a modification of the previously described method (Petrova and Isaeva, 2014). The sciatic nerves of recipient rats were lesioned by application of a ligature for $40 \mathrm{~s}$ at the level of the upper third of the thigh. A cell suspension $\left(5 \times 10^{4}\right.$ in $5 \mu$ medium $)$ was infused under the perineurium of the nerve trunk by a thin glass cannula. The surgery was conducted under an MBS-2 microscope (LOMO, Russia) under aseptic conditions.

The animals were then kept in standard vivarium conditions and were killed after one and five to seven days by an overdose of ethyl ether vapor. The nerve segments containing the transplant were fixed in a zinc-ethanol-formaldehyde solution according to the method of Korzhevskii et al. (2014). The material was embedded in paraffin after dehydration in alcohols of increasing concentration. The sections ( $5 \mu \mathrm{m}$ in thickness) were prepared using rotary microtome (RM 2125RT Leica, Germany) and were mounted on silane-treated glass slides (HistoBond, Germany). Histological slides were stained with toluidine blue, astra-blue and aniline blue.

\section{IMMUNOHISTOCHEMISTRY}

Immunohistochemical reaction to vimentin was used to characterize cultured MSCs. For light microscopy, immunohistochemical labeling was performed using murine monoclonal antibodies to vimentin (clone V-9) (Dako, Denmark) diluted $1: 100$. This immunohistochemical reaction was carried out on the culture of MSCs, directly in the culture flasks. After that, reagents from the EnVision+System Labeled Polymer_HRP AntiMouse kit (K4001, Dako, Denmark) were used. 3'3-diaminobenzidine (DAB+ kit) (Dako, Denmark) was used as a chromogen to visualize the reaction product. Some of the samples were additionally stained with astra-blue dye. Histological slides were analyzed using a light microscope Leica DM750 (Germany), and photos were taken using the camera ICC50 (Leica, Germany). A LAS EZ software (Leica, Germany) was used for image processing.

The transplanted mesenchymal stem cells of the graft were identified by immunohistochemical reaction to BrdU. After the standard procedure of deparaffinization and rehydration, sections were exposed to heat- 

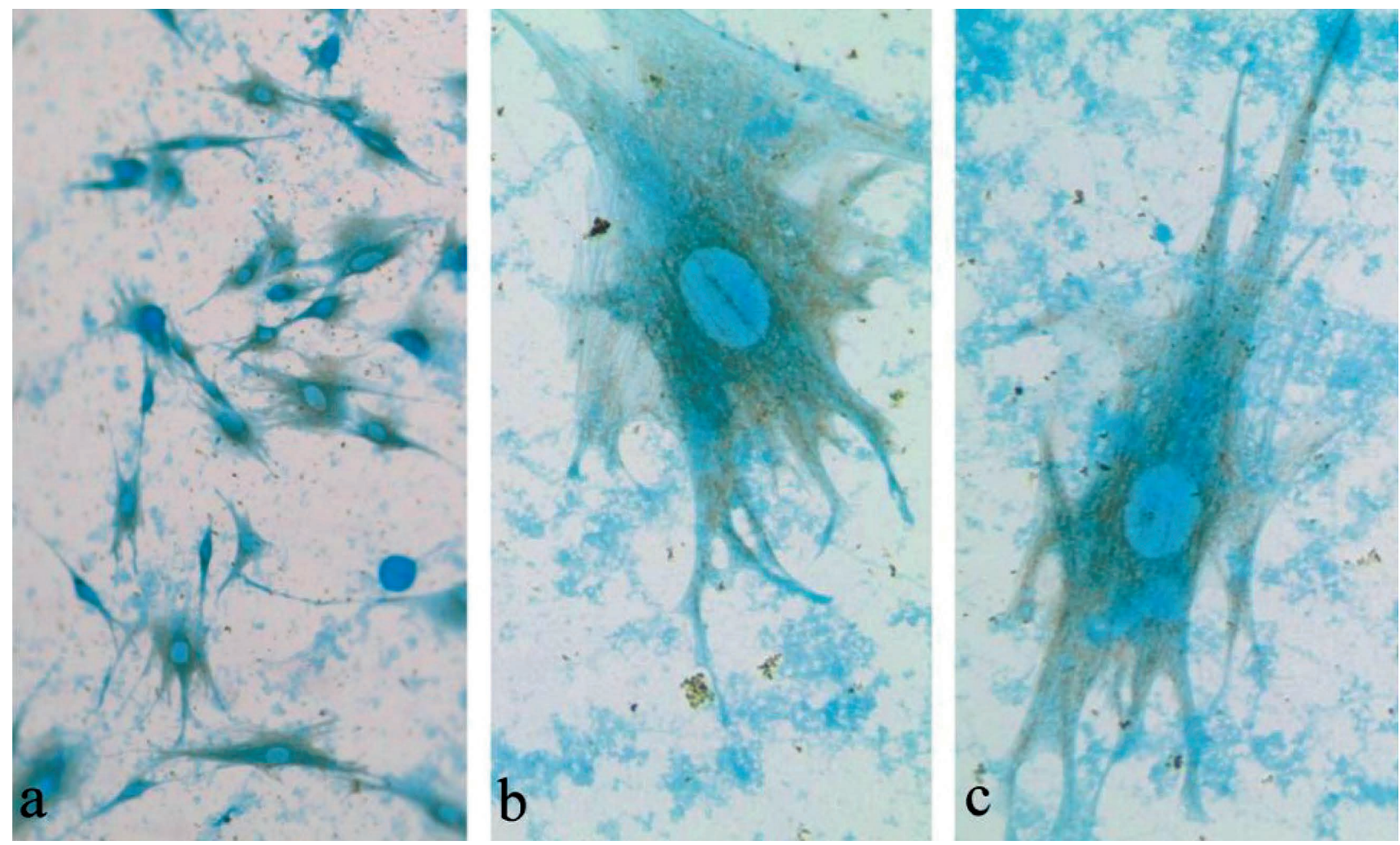

Fig. 1. MSCs in a culture flask. Immunohistochemical reaction to vimentin, astra-blue staining $\times 400(a), \times 1000(b, c)$

induced antigen retrieval (HIAR), followed by blocking endogenous peroxidase. Monoclonal antibodies to BrdU (Bu20a clone, Dako, Denmark, at a dilution 1: 100) were used. For light microscopy, reagents from the EnVision+System Labeled Polymer_HRP AntiMouse kit (K4001, Dako, Denmark) and 3'3-diaminobenzidine (DAB+ kit) (Dako, Denmark) were used. For fluorescence microscopy, biotinylated anti-mouse antibodies and streptavidin, conjugated with fluorescent carbocyanine dye (Cy2, Jackson ImmunoResearch, USA) were applied. Immunohistochemical marking of the perineurium on longitudinal sections through the nerve was also performed, using polyclonal antibodies to Claudin-1 (Dako, Denmark). The anti-rabbit secondary antibodies, conjugated with TRITC (Dako, Denmark) were used. The sections were examined and photographed using a fluorescence microscope: Leica DM2500, Leica DFC420 digital camera (Leica, Germany) and a fluorescent Nikon N-SIM\&N-STORM Super-Resolution Microscope (Nikon, Japan).

\section{Results}

This work examined bone marrow MSCs of the second passage. Adhesiveness is a characteristic property of MSCs in culture. This made it possible to study MSCs directly in culture flasks. The MSCs were fixed and stained just in the cell culture flasks. Astra-blue staining of the MSCs revealed their morphological features. MSCs are fibroblast-like cells with processes and a rounded or oval nucleus. Immunohistochemical reaction to vimentin an intermediate filament protein - was applied. It was found that vimentin is present in the cytoplasm of cultured MSCs (Fig. 1).

A suspension of the cultured MSCs was prepared for transplantation. Three days before the application of the cells, BrdU was added to the cultured medium. To make sure that the BrdU was absorbed into the MSCs, a smear of suspension cells was prepared, and BrdU immunohistochemistry was performed on these smears. Analysis of histological samples showed BrdU presence in most MSCs: the brown-colored nucleus indicates BrdU uptake into the cell (Fig. 2a). Therefore, BrdU-labeled MSCs can easily be distinguished from the recipient's cells five to seven days after transplantation under the perineurium of the sciatic nerve.

Five to seven days after surgery, the injured nerve fibers of recipients showed signs of Wallerian degeneration. We observed an increase of the mononuclear cells number and the appearance of nerve fiber swelling, the dilatation of blood vessels, and the thickening of nerve sheaths. The fragmentation of the axons and the myelin debris could not be detected because of the applied fixation and histological processing of the material. 

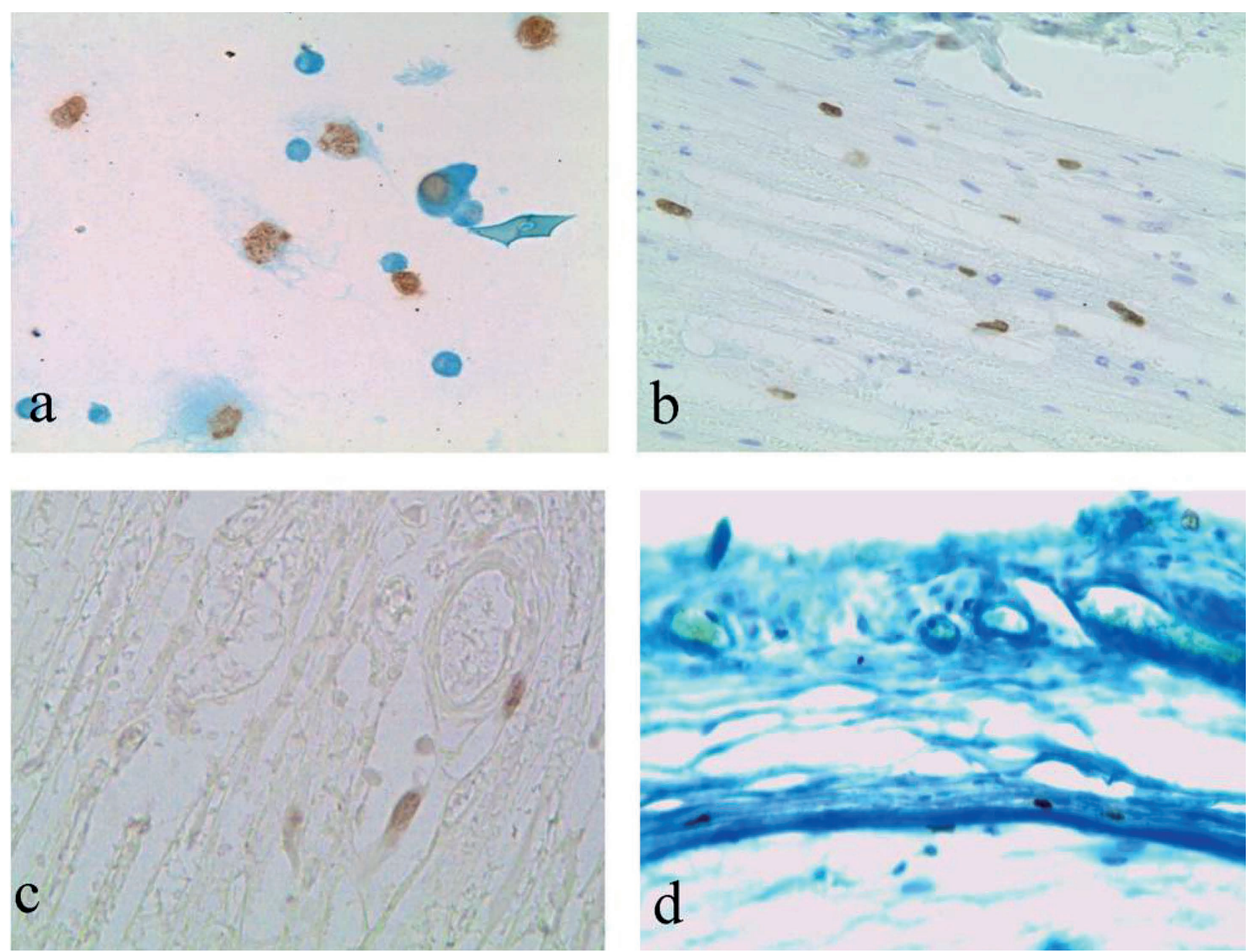

Fig. 2. BrdU-containing MSCs in a smear (a), in the sciatic nerve 1 day after transplantation (b, c), in the perineurium 5 days after transplantation (d). Immunohistochemical reaction on BrdU (a-d), astra-blue staining (a), toluidine blue staining (b), anilin blue staining (d). $\times 400, \times 100$.

Analysis of the sections showed that the number of transplanted MSCs in the nerve is quite small one (Fig. 2b, c) and five to seven (Fig. 2d) days after transplantation. The cells labeled with BrdU were detected in the nerve trunk one day after transplantation. It was found that clusters of BrdU-containing cells were located between the recipient nerve fibers, endogenous Schwann cells, fibroblasts and blood vessels (Fig. 2c) of the nerve trunk. Only single BrdU-labeled cells were found in the endoneurium of the recipient nerve trunk. Transplanted MSCs labeled with BrdU were found mainly in the epineurium and in the perineurium (Fig. 3).

The epineurium is the outer connective-tissue sheath of the nerve. It consists of blood vessels, adipose tissue, connective tissue cells and collagen fibers. The transplanted cells were revealed in the walls of blood vessels and in the adipose tissue. Some of the adipocyte nuclei contained BrdU (Fig. 3b). These BrdU-containing large cells have a round or polygonal shape and contain fat vacuoles, with the nucleus displaced to the periphery and a thin border of cytoplasm.
Some of the transplanted BrdU-labeled MSCs were found in the perineurium (Fig. 2d, 3a, 4). The perineurium is a layering of specialized cells that lies close to the epineurium and surrounds and protects the nerve fibers of the endoneurium. There are three zones of perineurium on the sections stained with toluidine blue (Fig. 2d). The inner zone is separated from the endoneurium by the subperineurial space and is formed by a layer of perineurial cells with several tight junctions. The intermediate zone consists of several layers of cells. The external zone is the transition area between the perineurium and epineurium, where the laminated structure of perineurial cells is lost and several wide bundles of collagen, similar to those found in the epineurium, can be observed. Tight junction proteins (ZO-1, occludin, and claudins) are present in perineurial cells. Claudine1 is one of the immunohistochemical markers of perineurial cells. Using fluorescence microscopy and antibodies to Claudine 1, we studied the inner layer of the perineurium. In Fig. 4 the protein tight contacts of the perineurial cells are colored red. It can be seen that transplanted 

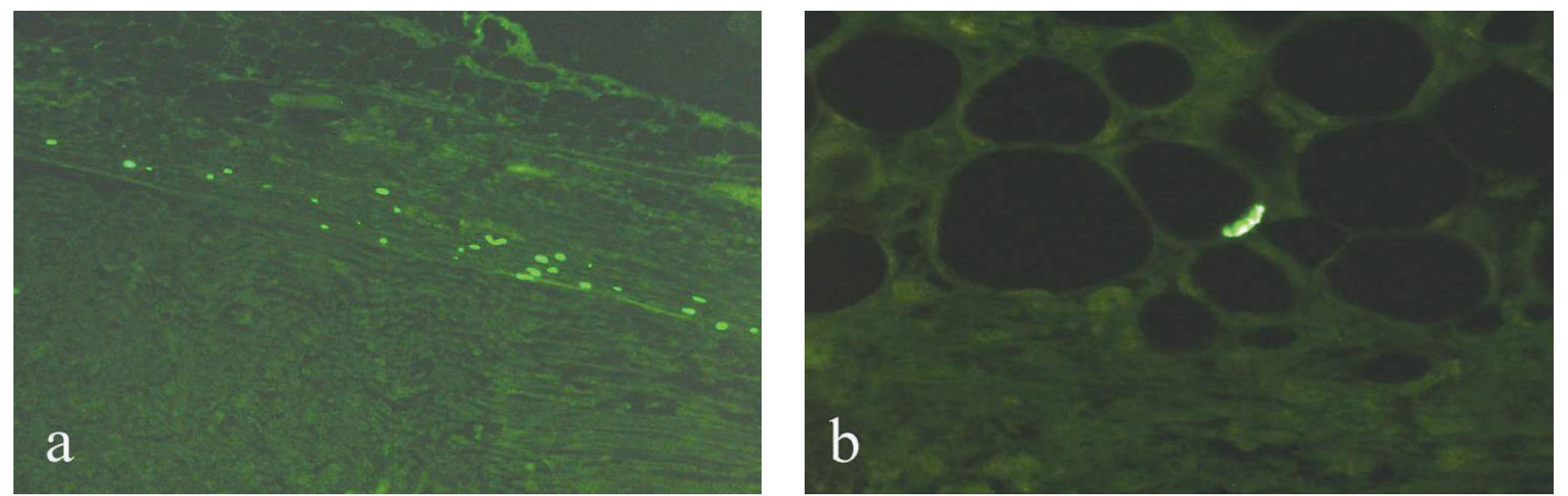

Fig. 3. BrdU-labeled MSCs in the connective tissue nerve sheaths (a) and adipocyte in adipose tissue of the recipient epineurium (b) 7 days after transplantation MSCs in the rat sciatic nerve. Immunohistochemical reaction on BrdU. Fluorescence microscopy. $\times 100, \times 600$.
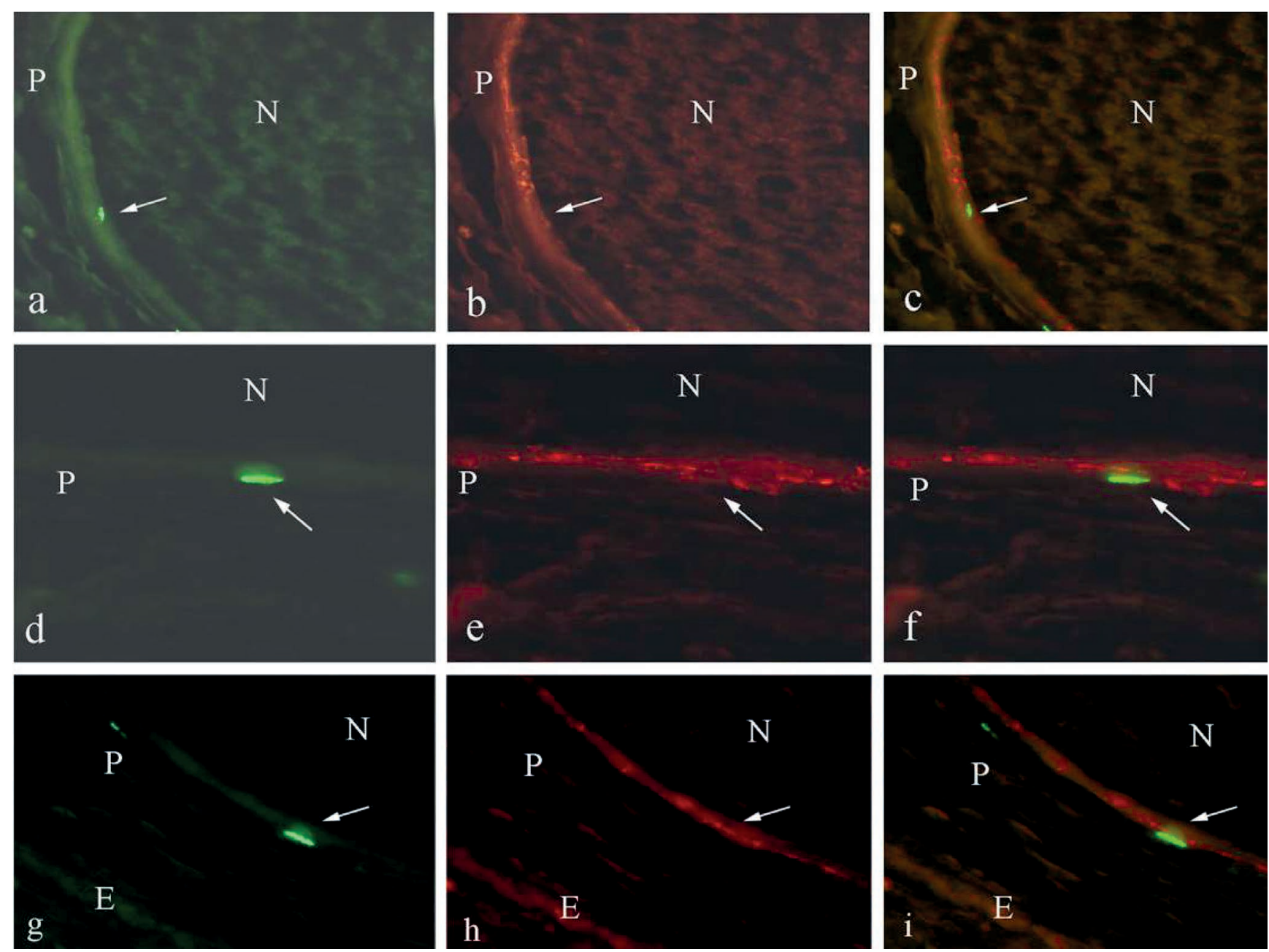

Fig. 4. BrdU-labeled (arrows) transplanted cells in the recipient perineurium 7 days after transplantation in the rat sciatic nerve. Immunohistochemical reaction to $\operatorname{BrdU}(a, d, g)$. Immunohistochemical reaction to claudin1 (b, e, h). Double positive staining for claudin1 (red) and BrdU (green) $(c, f, i) . N-$ endoneurium of the recipient's nerve; $\mathrm{P}-$ perineurium; $\mathrm{E}-$ epyneurium. Fluorescence microscopy. $\times 600$. 

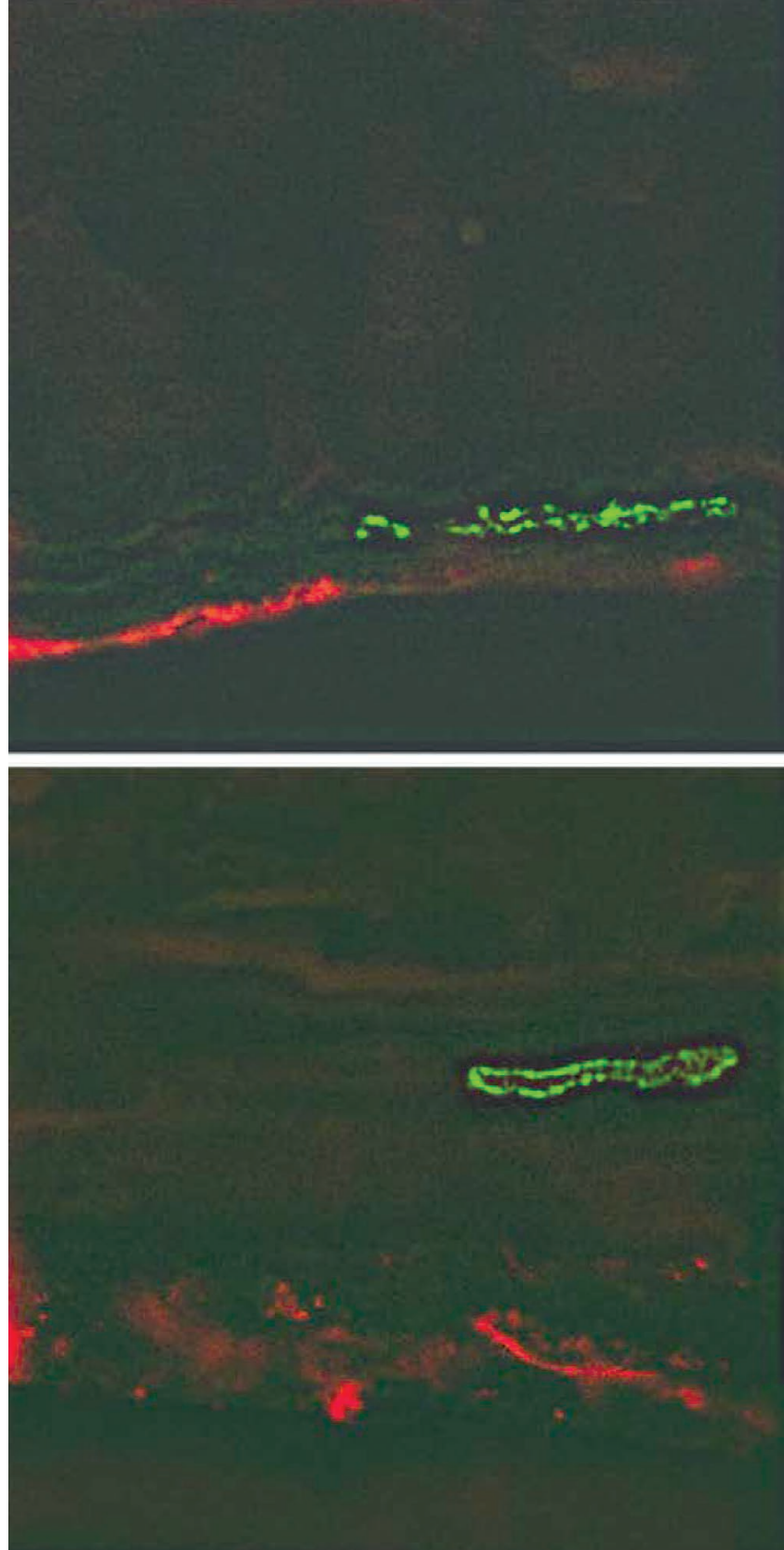

Fig. 5. Cell nucleus morphology of transplanted BrdU-labeled cells in the perineurium of the recipient 7 days after operation. Double positive staining for claudin1(red) and BrdU (green). $\times 2000$.

BrdU-containing MSCs are located near this layer. The nuclei of the transplanted cells are flattened (Fig. 5). This form is typical for perineurium cells. Thus, according to localization of MSCs and the shape of their nuclei, we can conclude that they have differentiated into perineural cells.

\section{Discussion}

Bone marrow mesenchymal stem cells (MSCs), which are widely used in regenerative medicine in recent years, were used in this work. MSCs were first detected in bone marrow stroma by Friedenstein and colleagues (Friedenstein, Piatetzky-Shapiro, and Petrakova, 1966; Friedenstein, Chailakhyan, and Gerasomov, 1987). MSCs are mesodermal cells that form connective tissue throughout the body and give rise to fibroblasts, osteoblasts, chondrocytes, fat (Pitterger et al., 1999) and endothelial cells (Dennis and Charbord, 2002). Followup studies have described the surface markers of MSCs (Pulin, Saburina, and Repin, 2008) and have defined the ability of these cells to secrete various biologically active substances. It has been shown that MSCs are able to produce growth and trophic factors such as epidermal growth factor (EGF), hepatocyte growth factor (HGF), fibroblast growth factor (FGF), transforming growth factor $\beta$ (TGF $\beta$ ), BDNF, GDNF, NGF and extracellular matrix proteins (Chen et al., 2007; Brochlin et al., 2009). The rat bone marrow mesenchymal stem cells used in the present study were previously characterized by Zin'kova et al. (2007). Their phenotype $\left(97 \%-\mathrm{CD} 90^{+}\right)$ corresponds to the phenotype of bone marrow multipotent stromal cells. The cells we use have morphological features inherent in MSCs: cells exhibit the adhesive property and contain the intermediate filaments protein - vimentin - in the cytoplasm (Fig. 1). In research conducted on different types of animals, it has been found that the introduction of bone marrow MSCs into the nerve or conduit connecting the ends of a damaged nerve promotes the regeneration of nerve fibers (review: Petrova, 2015). However, the mechanisms of this effect are poorly understood. The investigation of MSC differentiation potential and of the processes occurring with MSCs after transplantation into the recipient tissues can explain the stimulation of regeneration. The need for research on the fate of transplanted mesenchymal stem cells also explains the fact that, in recent years, a large number of clinical research has been conducted in this direction (Xue et al., 2011; Li et al., 2013; Gallyamov et al., 2015; Bogov et al., 2016; Cohen et al., 2018).

In the present study, we carried out subperineural allotransplantation of rat MSCs into injured nerves of the recipients. Five to seven days after surgery, we detected most of BrdU-immunopositive cells not in the endoneurium, where they were placed, but in the outer nerve shells. We assume that MSCs migrate from the endoneurium into the nerve sheaths. MSCs are known to have a high migration potential. The number of cells surviving after the transplantation was small, since apparently most of the transplanted cells died. The question of how long exogenous MSCs can maintain their viability in recipient tissues is debatable. Some authors have detected pre-labeled MSCs even a few months after transplantation (Evaristo-Mendonca et al., 2018). However, other authors note that MSCs survive about 10 days after transplantation into the brain, and by 20 days they have completely degenerated (Loseva et al., 2012). 
Regarding the differentiation potential of bone marrow MSCs, this issue needs to be discussed separately. There is evidence that MSCs are able to differentiate into various types of cells (cardiomyocytes, astrocytes, neurons and others) under certain conditions in vitro (Martin et al., 2002; Wislet-Gendebien et al., 2005; Yang et al., 2008) and in vivo (Kopen, Prockop, and Phinney, 1999). Several studies demonstrate the potential of MSCs to differentiate into Schwann cells (Chen et al., 2006; Frattini et al., 2012). Schwann cells or neurolematocytes are glial elements of the peripheral nervous system that perform many important functions and provide a microenvironment for the regenerating axons in the damaged nerve (Jessen, Mirsky, and Lloyd, 2015). Schwann cells represent the majority of the cellular elements of the nerve. They are located along the nerve fibers. The nuclei of the Schwann cells have a specific elongated shape and differ from the nuclei of endotheliocytes and fibroblasts, which make up less than $5 \%$ of the nerve trunk. It has been shown that MSCs can be stimulated towards differentiation into Schwann cells by their cocultivation with dorsal root ganglion neurons (Chen et al., 2006) or by the addition of glial growth factor-2 (GFG-2) into the culture medium. Directional differentiation of bone marrow mesenchymal stem cells using GFG was done before their transplantation into the nerve (Tohill, Mantovani, Wiberg, and Terenghi, 2004). These MSCs, labeled by retroviral gene transfer with green fluorescent protein, were transplanted into the damaged nerve. 15 days after transplantation, they maintained the ability to express Schwann cell markers and improved nerve regeneration.

In this study, we have shown that some of the grafted MSCs are found in the epineural sheath and differentiate into adipose tissue cells five to seven days after transplantation into the nerve. One of the characteristic of MSCs isolated from bone marrow (or other sources) is their in vitro differentiation in three directions: bone, cartilage and adipose tissue cells. Therefore, the detection of BrdU-labeled adipocytes indicates that the transplanted cells realize their potencies when they are in a characteristic microenvironment - in the loose connective tissue of the epineurium. The detection of MSCs that had differentiated into perineurium cells was unexpected. Many authors have investigated the structure and function of this nerve sheath (Chumasov, 1975; Zochodne, 2008). The perineurium is characterized by the presence of occluding junctions (zonula occludens or tight junctions) and gap junctions (zonula adherens), which are necessary for the implementation of the neuro-tissue barrier. Perineurial cells have polygonal forms, a thin, flat cytoplasm and form several layers; the basement membranes are placed between them. Extracellular matrix proteins such as laminin, fibronectin, collagen and glycosaminoglycans are present in the perineurium.
Apparently, it is the presence of these proteins that creates a favorable biological environment for survival of MSCs and for their differentiation into perineurium cells.

The origin of perineurium cells in ontogenesis has been a subject of discussion for a long time (Zochodne, 2008). It was established that perineurium cells do not have a neural crest cell origin, but instead derive from mesenchymal cells, i.e. fibroblasts, which surround adjacent nerve fibers in formation (Bunge et al., 1989; Joseph et al., 2004). This study once again confirms the mesenchymal origin of perineurium cells. The effect of extracellular matrix proteins on the differentiation of MSCs has been shown in studies performed in vitro (Gronthos, Simmons, Graves, and Robey, 2001) and in vivo (Gonzalez-Perez et al., 2018).

Some modern scientific literature presents data on the stimulation of nerve regeneration with the use of MSCs obtained not from bone marrow, but from other sources (Fairbairn et al., 2015). From our point of view, the research of Japanese authors Tamaki et al. (2014) was performed flawlessly and is particularly interesting. In this work, MSCs were derived from the skeletal muscle of green fluorescent protein transgenic mice, and they were transplanted into severely crushed mouse nerves. It turned out that these cells, being in a new microenvironment, differentiated into both Schwann cells and the cells of the recipient nerve sheath. A comparative study showed that MSCs derived from skeletal muscle have a greater differentiation potential than MSCs of bone marrow. It is important to note that the search for new tissue sources of MSCs for transplantation into nerves is associated with the danger of negative consequences for the recipient. For example, MSCs derived from skeletal muscle can lead to the appearance of a tumor after transplantation into the nerve, which was shown in 2013 (Lavasani et al., 2013).

In scientific literature there is no unified opinion on the mechanisms of MSC influence on nerve regeneration. Using RT-PCR, it has been shown that MSCs produce NGF $\beta$, BDNF, NGF and NT-3 (Peng et al., 2011). Due to their ability to synthesize trophic factors, they stimulate the proliferation of recipient Schwann cells (Ribeiro-Resende et al., 2012). On the other hand, the effect is related to the possible differentiation of MSCs into Schwann cells under the influence of trophic factors released from the proximal end of the cut nerve. However, this assumption does not always find experimental confirmation (Shen et al., 2010; Evaristo-Mendonca et al., 2018). In this study, we were also unable to show the possibility of differentiating MSCs into Schwann cells.

There is evidence of vascularization improvement in the damaged nerve due to the use of cellular therapy (Tamaki et al., 2014; Petrova, Isaeva, Kolos, and Korzhevskii, 2018; Evaristo-Mendonca et al., 2018). In our 
previous work, we showed that the number of microvessels in the damaged rat nerve trunk increases one and a half times after the application of MSCs (Petrova, 2018; Evaristo-Mendonca et al., 2018). Our current explanation of this fact is that MSCs produce angiogenic factors. Some experiments on MSC transplantation into the ischemic heart or liver demonstrate that these cells can differentiate into endotheliocytes of blood vessels (Yoon et al., 2005; El'chaninov et al., 2017). The question about the differentiation of MSCs into endothelial cells after their transplantation into a nerve or conduit is debatable. This differentiation has been noted only in individual works (Petrova, Isaeva, and Korzhevskii, 2016; Evaristo-Mendonca et al., 2018). The data we obtained earlier, using light microscopy, showed that cells transplanted into damaged nerves localize to the walls of the emerging blood vessels (Petrova, Isaeva, and Korzhevskii, 2016). This fact needs to be confirmed with double marking in our further studies. This year, direct evidence has suggested that MSCs, developing in the conduit that connects the proximal and distal nerve stumps, can differentiate into vascular smooth muscle cells (Evaristo-Mendonca et al., 2018).

In the present study we have shown that MSCs obtained from the bone marrow of Wistar-Kyoto rats survive for seven days after allotransplantation into the damaged sciatic nerve. Most of the transplanted cells are localized in the connective tissue sheaths of the recipient nerve. We found that a certain number of transplanted cells differentiate into adipocytes and perineurium cells. Our further studies will show if such transplantation has a stimulating effect on nerve regeneration.

\section{Acknowledgements}

The authors thank the head of the Department of Electron Microscopy (A. N. Belozersky Institute of Physico-Chemical Biology of the Lomonosov Moscow State University), Dr. Sci. I. I. Kireev, for the opportunity to work on a fluorescent Nikon N-SIM\&N-STORM Super-Resolution Microscope.

\section{References}

Bogov, A. A., Masgutov, R. F., Rizvanov, A. A., Salafutdinov, I. I., Gallyamov, A. R., Hannanova, I. G., and Ahtyamov, I. F. 2016. Treatment of traumatic injuries of peripheral nerves with the use of regeneration stimulators. Annals of plastic, reconstructive and aesthetic surgery 1: 64-65.

Brohlin, M., Mahay, D., Novikov, L. N., Terenghi, G., Wiberg, M., Shawcross, S. G., and Novikova, L. N. 2009. Characterisation of human mesenchymal stem cells following differentiation into Schwann cell-like cells. Neuroscience Research 64:41-49. https://doi.org/10.1016/j. neures.2009.01.010.

Bunge, M.B., Wood, P.M., Tynan, L.B. Bates, M. L., and Sanes, J.R. 1989. Perineurium originates from fibroblasts: demonstration in vitro with a retroviral marker. Science 243(4888):229-231. https://doi.org/10.1126/science. 2492115
Chen, X., Wang, X. D., Chen, G. Lin, W. W., Yao, J., and Gu X. S. 2006. Study of in vivo differentiation of rat bone marrow stromal cells into schwann cell-like cells. Microsurgery 26(2): 111-115. https://doi.org/10.1002/micr.20184

Chen, C.J., Ou, Y.C., Liao, S. L., Chen, W.Y., Wu, C.W., Wang, C. C., Wang, W. Y., Huang, Y. S., and Hsu, S. H. 2007. Transplantation of bone marrow stromal cells for peripheral nerve repair. Experimental Neurology 204: 443445. https://doi.org/10.1016/j.expneurol.2006.12.004

Chumasov, E. I. 1975. On the structure of perineurium of the peripheral nervous system. Arkhiv Anatomii, Gistologii $i$ Embriologii 68(4):29-34.

Cohen, J.A., Imrey, P.B., Planchon, S. M., Bermel, R. A., Fisher, E., Fox, R.J., Bar-Or, A., Sharp, S. L., Skaramagas ,T.T., Jagodnik, P., Karafa, M., Morrison, S., Reese Koc, J., Gerson, S. L., and Lazarus, H. M. 2018. Pilot trial of intravenous autologous culture-expanded mesenchymal stem cell transplantation in multiple sclerosis. Multiple sclerosis 24(4):501-511. https://doi. org/10.1177/1352458517703802.

Dennis, J. E. and Charbord, P. 2002. Origin and differentiation of human and murine stroma. Stem Cells 20(3):205-214. https://doi.org/10.1634/stemcells.20-3-205

Dezawa, M., Takahashi, I., Esaki, M., Takano, M., and Sawada, H. 2001. Sciatic nerve regeneration in rats induced by transplantation of in vitro differentiated bone-marrow stromal cells. European Journal of Neuroscience 14:17711776. https://doi.org/10.1046/j.0953-816x.2001.01814.x

El'chaninov, A. V., Fatkhudinov, T. Kh., Arutyunyan, I. V., Makarov, A. V., Lokhonina, A. V. Eremina, I. Z., Bicherova, I. A., and Bol'shakova, G. B. 2017. Directions of allogeneic multipotent stromal cells differentiation in the regenerating liver. Journal of Anatomy and Histopathology 6(4):15-20. https://doi.org/10.18499/2225-7357-2017-64-15-20

Evaristo-Mendonca, F., Carrier-Ruiz, A., de Siqueira-Santos, R., Campos, R. M.P., Rangel, B., Kasai-Brunswick, T. H. and Ribeiro-Resende, V.T. 2018. Dual contribution of mesenchymal stem cells employed for tissue engineering of peripheral nerves: trophic activity and differentiation into connective-tissue cells. Stem Cell Reviews and Reports 14(2): 200-212. https://doi.org/10.1007/s12015-0179786-5.

Fairbairn, N.G., Meppelink, A.M., Ng-Glazier, J., Randolph, M.A., and Winograd, J.M. 2015. Augmenting peripheral nerve regeneration using stem cells. World Journal of Stem Cells 7(1):11-26. https://doi.org/10.4252/ wjsc.v7.i1.11.

Frattini, F., Lopes, F. R., Almeida, F. M. Rodrigues, R. F., Boldrini, L. C., Tomaz, M.A., Baptista, A. F., Melo, P. A., and Martinez, A. M. 2012. Mesenchymal stem cells in a polycaprolactone conduit promote sciatic nerve regeneration and sensory neuron survival after nerve injury. Tissue Engeneering. Part. A. 18(19-20):2030-2039. https:// doi.org/10.1089/ten.TEA.2011.0496.

Friedenstein, A. J., Piatetzky-Shapiro, I. I., and Petrakova, K. V. 1966. Osteogenesis in transplants of bone marrow cells. Journal of Embryology and Experimental Morphology 16: 581-390.

Friedenstein, A.J., Chailakhyan, R. K., and Gerasimov, U. V. 1987. Bone marrow osteogenic stem cells: in vitro cultivation and transplantation in diffusion chambers. Cell Tissue Kinetics 20:263-272. https://doi. org/10.1111/j.1365-2184.1987.tb01309.x

Gallyamov, A.R., Masgutov, R. F., Rizvanov, A.A., Salafutdinov, I. I., Ahtyamov, I.F., Bogov, A.A.Jr., and Bogov, A. A. 2015. Stromal vascular fraction in peripheral nerve regeneration. International Journal of Develop- 
mental Neuroscience 47(A): 32. http://doi.org/10.1016/j. ijdevneu.2015.04.092

Gonzalez-Perez, F., Hernández, J., Heimann, C., Phillips, J. B., Udina, E. and Navarro, X. 2018. Schwann cells and mesenchymal stem cells in laminin- or fibronectinaligned matrices and regeneration across a critical size defect of $15 \mathrm{~mm}$ in the rat sciatic nerve. Journal of Neurosurgery: Spine 28(1):109-118. https://doi. org/10.3171/2017.5.SPINE161100

Gronthos, S., Simmons, P.J, Graves, S. E., and Robey, P. G. 2001. Integrin-mediated interactions between human bone marrow stromal precursor cells and the extracellular matrix. Bone (2):174-181. https://doi.org/10.1016/ S8756-3282(00)00424-5

Jessen, K. R., Mirsky, R., and Lloyd, A. C. 2015. Schwann Cells: Development and Role in Nerve Repair. Cold Spring Harbor Perspectives in Biology 7(7):a020487. https://doi. org/10.1101/cshperspect.a020487.

Joseph, N. M., Mukouyama, Y.S., Mosher, J.T., Jaegle, M., Crone, S. A., Dormand, E. L., Lee, K. F., Meijer, D., Anderson, D.J., and Morrison, S.J. 2004. Neural crest stem cells undergo multilineage differentiation in developing peripheral nerves to generate endoneurial fibroblasts in addition to Schwann cells. Development 31:5599-5612. https://doi.org/10.1242/dev.01429

Kingham, P. J., Kalbermatten, D. F., Mahay, D., Armstrong, S. J., Wiberg, M., and Terenghi, G. 2007. Adipose-derived stem cells differentiate into a Schwann cell phenotype and promote neurite outgrowth in vitro. Experimental Neurology 207: 267-274. https://doi.org/10.1016/j.expneurol.2007.06.029

Kopen, G. C., Prockop, D. J., and Phinney, D. G. 1999. Marrow stromal cells migrate throughout forebrain and cerebellum, and they differentiate into astrocytes after injection into neonatal mouse brains Proceedings of the National Academy of Sciences, U S A 96(19):10711-10716.

Korzhevskii, D. E., Sukhorukova, E. G., Gilerovich, E. G., Petrova, E. S., Kirik, O. V., and Grigor'ev, I. P. 2014. Advantages and disadvantages of zinc-ethanol-formaldehyde as a fixative for immunocytochemical studies and confocal laser microscopy Neuroscience and Behavioral Physiology 44:542-545. https://doi.org/10.1007/s11055-014-9948-8

Lavasani, M., Pollett, J.B., Usas, A., Thompson, S. D., Pollett, A. F., and Huard, J. 2013. The microenvironmentspecific transformation of adult stem cells modelsmalignant triton tumors. PLoS One 8(12):e82173. https://doi. org/10.1371/journal.pone.0082173.

Li, Y., Hu, G., and Cheng, Q. 2015. Implantation of human umbilical cord mesenchymal stem cells for ischemic stroke: perspectives and challenges Frontiers in Medicine 9:2029. https://doi.org/10.1007/s11684-014-0371-x.

Li, Z., Qin, H. Feng, Z., Liu, W., Zhou, Y., Yang, L., Zhao, W., and Li, Y. 2013. Human umbilical cord mesenchymal stem cell-loaded amniotic membrane for the repair of radial nerve injury. Neural Regeneration Research 8(36):3441-3448. https://doi.org/10.3969/j.issn.16735374.2013.36.010

Loseva, E. V., Loginova, N. A., Kurskaya, O. V., Podgornyi, O. V., Poltavtseva, R. A., Aleksandrova, M.A., Marei, M. V., Sukhikh, G.T., and Chailakhyan, R. K. 2012. Effects of neurotransplantation of cultured human neural and mesenchymal stem cells on learning and the state of the brain in rats after hypoxia. Neuroscience and Behavioral Physiology 42(5):462-471. https://doi.org/10.1007/ s11055-012-9588-9.

Martin, D. R., Cox, N. R., Hathcock, T. L., Niemeye,r G. P., and Baker, H.J. 2002. Isolation and characterization of multipotential mesenchymal stem cells from feline bone mar- row. Experimental Hematology 30(8):879-886. https://doi. org/10.1016/S0301-472X(02)00864-0

Masgutov, R., Masgutova, G., Mukhametova, L., Garanina, E., Arkhipova, S. S., Zakirova, E., Mukhamedshina, Y. O., Margarita, Z., Gilazieva, Z., Syromiatnikova, V., Mullakhmetova, A., Kadyrova, G., Nigmetzyanova, M., Mikhail, S. Igor, P., Yagudin, R., and Rizvanov, A. 2018. Allogenic adipose derived stem cells transplantation improved sciatic nerve regeneration in rats: autologous nerve graft model. Frontiers in Pharmacology 9:86. https://doi. org/10.3389/fphar.2018.00086

Petrova, E. S. 2015. Injured nerve regeneration using cellbased therapies: current challenges. Acta Naturae 7: 38-47.

Petrova E.S. 2018. Potentials to differentiation of mesenchemical stem cells and stimulation of neuroregeneration. Ontogenez 49(4):1-14. https://doi.org/10.1134/ S0475145018010032

Petrova, E. S., Isaeva, E. N, and Korzhevskii, D. E. 2016. Rat mesenchymal stem cells differentiate to endothelial cells after allotransplantation into the damaged nerve. Transplantation Open 1(1):1-4. https://doi.org/10.15761/ JTO.1000101

Petrova, E. S., and Isaeva, E. N. 2014. Study of effect of embryonic anlage allografts of the rat spinal cord on growth of regenerating fibers of the recipient nerve. Biology Bulletin 41:479-485. https://doi.org/10.1134/ S1062359014060089

Petrova, E. S., Isaeva, E. N., Kolos, E. A., and Korzhevskii, D. E. 2018. Vascularization of the damaged nerve under the effect of experimental cell therapy. Bulletin of Experimental Biology and Medicine 165(1):161-165. https://doi. org/10.1007/s10517-018-4120-z

Pitterger, M. F., Mackay, A. M., Beck, S. C., Jaiswal, R. K., Douglas, R., Mosca, J.D., Moorman, M.A., Simonetti, D.W., Craig, S., and Marshak, D. R. 1999. Multilineage potential of adult human mesenchymal stem cells. Science 284:143147. https://doi.org/10.1126/science.284.5411.143

Pulin, A. A., Saburina, I. N., and Repin, V.S. 2008. Surfaces markers of human bone marrow multipotent mesecnhymal stromal cells. Genes and cells 3(3):25-30.

Ribeiro-Resende, V. T., Carrier-Ruiz, A., Lemes, R. M., Reis, R. A., and Mendez-Otero, R. 2012. Bone marrow-derived fibroblast growth factor-2 induces glial cell proliferation in the regenerating peripheral nervous system. Molecular Neurodegeneration 7:34. https://doi.org/10.1186/17501326-7-34

Shchanitsyn, I. N., Ivanov, A. N., Bazhanov, S. P., Ninel', V. G., Puchin'jan, D. M., Norkin, I. A. 2017. Stimulation of peripheral nerve regeneration: current status, problems and perspectives. Uspehi fiziologicheskih nauk 48(3):93112.

Shen, J., Duan, X. H., Cheng, L. N., Zhong, X. M., Guo, R. M., Zhang, F., Zhou, C. P., and Liang, B. L. 2010. In vivo MR imaging tracking of transplanted mesenchymal stem cells in a rabbit model of acute peripheral nerve traction injury. Journal of Magnetic Resonance Imaging 32(5):10761085. https://doi.org/10.1002/jmri.22353.

Sokolova, I. B., and Polyntsev, D.G. 2017. The efficacy of mesenchymal stem cells for the improvement of cerebral microcirculation in spontaneously hypertensive rats. Cell and Tissue Biology 11(5):343-348. https://doi. org/10.1134/S1990519X1705008X

Southwell, D. G., Nicholas, C. R., Basbaum, A. I., Stryker, M. P., Kriegstein, A. R., Rubenstein, J. L., and Alvarez-Buylla, A. 2014. Interneurons from embryonic development to cell-based therapy. Science 344:1240622. https://doi. org/10.1126/science.1240622 
Stagg, J. and Galipeau, J. 2013. Mechanisms of immune modulation by mesenchymal stromal cells and clinical translation. Current Molecular Medicine 13(5):856-867. https:// doi.org/10.2174/1566524011313050016

Tamaki, T., Hirata, M., Soeda, S., Nakajima, N., Saito, K., Nakazato, K., Okada, Y., Hashimoto, H., Uchiyama, Y., and Mochida, J. 2014. Preferential and comprehensive reconstitution of severely damaged sciatic nerve using murine skeletal muscle-derived multipotent stem cells. PLoS One 9(3):e91257. https://doi.org/10.1371/journal. pone.0091257

Tohill, M., Mantovani, C., Wiberg, M., and Terenghi, G. 2004. Rat bone marrow mesenchymal stem cells express glial markers and stimulate nerve regeneration. Neuroscience Letters 362(3):200-203. https://doi.org/10.1016/j.neulet.2004.03.077

Walsh, S. and Midha, R. 2009. Use of stem cells to augment nerve injury repair. Neurosurgery 65:A80-86. https://doi. org/10.1227/01.NEU.0000335651.93926.2F

Wislet-Gendebien, S., Hans, G., Leprince, P., Rigo, J.M. Moonen, G., and Rogister, B. 2005. Plasticity of cultured mesenchymal stem cells: switch from nestin-positive to excitable neuron-like phenotype. Stem Cells 23(3):392402. https://doi.org/10.1634/stemcells.2004-0149

Wong, R. S. 2011. Mesenchymal stem cells: angels or demons? Journal of Biomedicine and Biotechnology 459510:1-8. https://doi.org/10.1155/2011/459510

Xue, G., He, M., Zhao, J., Chen, Y., Tian, Y., Zhao, B., and Niu, B. 2011. Intravenous umbilical cord mesenchymal stem cell infusion for the treatment ofcombined malnutrition nonunion of the humerus and radial nerve injury. Regenerative Medicine 6(6):733-741. https://doi.org/10.2217/ rme.11.83

Yang, J., Lou, Q., Huang, R., Shen, L., and Chen, Z. 2008. Dorsal root ganglion neurons induce transdifferentiation of mesenchymal stem cells along a Schwann cell lineage. Neuroscience Letters 445:246-251. https://doi. org/10.1016/j.neulet.2008.09.015

Yoon, Y.S., Wecker, A., Heyd, L., Park, J. S., Tkebuchava, T., Kusano, K., Hanley, A., Scadova, H., Qin, G., Cha, D. H., Johnson, K. L., Aikawa, R., Asahara, T., and Losordo, D. W. 2005. Clonally expanded novel multipotent stem cells from human bone marrow regenerate myocardium after myocardial infarction. Journal of Clinical Investigation 115(2):326-338. https://doi.org/10.1172/JCI200522326

Zin'kova, N. N., Sokolova, I. B., Viide ,S. K., Shvedova, E. V., Alexandrov, G. V., Kruglyakov, P. V., Polyntsev, D. G., and Gilerovich, E. G. 2007. Mesenchymal stem cell therapy of brain ischemic stroke in rats. Cell and Tissue Biology 1:389398. https://doi.org/10.1134/S1990519X07050033

Zhang, P., He, X., Liu, K., Zhao, F., Fu, Z., Zhang, D., Zhang, Q., and Jiang, B. 2004. Bone marrow stromal cells differentiated into functional Schwann cells in injured rats sciatic nerve. Artificial cells, blood substitutes, and immobilization biotechnology 32(4):509-518. https://doi.org/10.1081/ BIO-200039608

Zochodne, D. W. 2008. Neurobiology of Peripheral Nerve Regeneration. Cambridge, New York, Melbourne, Madrid, Cape Town, Singapore, Sao Paulo: Cambridge University Press. https://doi.org/10.1017/CBO9780511541759 